\title{
Adapting a math book to the arab world region: Benefits on the learning process
}

\author{
Saadia Khouyibaba \\ Department of mathematics and Statistics, American University of Sharjah, Sharjah, United Arab Emirates \\ For correspondence: skhouyibaba@aus.edu
}

\begin{abstract}
An instructor in the Arab world teaching a math course is used to the unfortunate situation where he wants to follow a well-known book whose reputation is long established and yet, all books he can find have been written in the western world, and none of them even allude to any of the specificities of the Arab world. The situation can even sometimes be squarely awkward in respected institutions rooted in traditional societies of the Arab world, where a professor enjoy an esteemed social status and is expected to have wisdom, but yet finds himself teaching some concepts and examples -although well written and sometimes mathematically critically important- which deal with irrelevant topics, such as income tax in countries where there are none, or frankly embarrassing ones, when gambling, alcohol consumption or others are at the forefront. Both students and educators ask themselves: can't there be more relevant examples for this part of world? Can't we use a book that takes into considerations, illustrates and values the society we are from? The idea of making an Arab World Edition for a textbook stems from that preoccupation. Indeed, we believe that such initiative is long overdue. The purpose of this paper is to highlight the benefits of the adaptation of a textbook to the world where a student lives and how a Math textbook can be adapted to the Arab world region. The Arab World version of the 13th edition of Haeussler, Paul and Wood's textbook "Introductory Mathematical Analysis for Business, Economics, and the Life and Social Sciences" by haeussler will be used for this purpose.
\end{abstract}

Keywords: Mathematics, Educations, Pedagogy

\section{Introduction}

Teaching mathematics in an Arab country with a book written in a Western world is a unique experience but sometimes complicated, not because of mathematical concepts; we all know that these are the same everywhere; math does not change from one country to another, but because of the fact that the book is not only written in a western country, it's written for western students. Indeed, a book written in a certain country always comes with applications completely taken from the real life of this country. Therefore, an Arab student is in a situation where he must handle applications from the real life of a citizen who lives thousands of kilometres from the Arab world. Also students are sometimes paying high price for their education, and even when this is not the case, many of them feel that they deserve to be taught mathematics using a book that takes then into considerations, illustrates and values the society they are from.

The idea of adapting a mathematical book to remedy this situation came in October 2010 as a part of Pearson's Arab World Edition. And the book chosen for this adaptation was the $13^{\text {th }}$ edition of "Introductory Mathematical Analysis for Business, Economics, and the Life and Social Sciences", by E. Haeussler, R. Paul and R. Wood

\section{About the adapted book}

"Introductory Mathematical Analysis for Business, Economics, and the Life and Social Sciences" by Ernest Haeussler, Richard Paul and Richard Wood is one of the finest on the topic of Business. This wellknown and established title is widely used by colleges and universities throughout the world. The long lasting popularity of the manual can be credited to presenting each topic in its upmost clarity and simplicity, in a structure allowing a thorough coverage of them. This certainly can be credited to 
the sheer writing skills of the authors but it is also based on sound pedagogical principles and hallmark features.

\section{Adaptation}

Making this adaptation has been a long and fascinating endeavor. This journey brought the author -and we hope the educator or student who reads these lines will feel the same- through a realm of mathematical applications that constitute a voyage both through mathematics and the Arab world. We could not escape the beauty of how far reaching mathematics is, and we were interested, amused and sometimes surprised or fascinated by the applications that carried us from one place to another, through these countries Arabs call home. Whoever is born in this region that stretches from the Atlantic shores of Northern Africa to the eastern shores of the Mediterranean Sea, and includes the whole Arabian Peninsula is acutely aware of the value and need for an Arab World version of an introductory mathematical textbook for Business, Economics and other Social Sciences. The four major changes that make this adaptation unique, helpful and appreciated in the Arab world institutions are:
A. Real world applications
B. Suppression and replacement of examples, pictures and inappropriate topics
C. English-Arabic Glossary
D. Biographies and Arabic contribution to mathematics

\section{A. Real world applications:}

Most instructors and students will agree that the quality of a textbook goes with the quality of the applications problems that this book contains. For that, hundreds of real life examples and problems about the Arab World have been incorporated and solved in details. These problems take the reader from the population growth of Cairo, to the Infant Mortality rate in Tunisia, the life expectancy in Iraq, the divorce rate in Algeria, the unemployment rate in Saudi Arabia, the exports and imports of Kuwait, the oil production in Tunisia and Saudi Arabia, the CPI of Libya, the GDC of Lebanon, the population of Bahrain in the age group of 15 to 65, the number of doctors in Jordan, the number of female teachers in Saudi Arabia and the size of Egypt's public debt. They also include popular products of the region and local companies like Air Arabia, Royal Jordanian Airline and Emirates, oil companies such as Aramco, postal companies like Aramex, telecommunication providers such as Etisalat and Menatel, and the stocks of Emaar. Regional trends are also covered in these problems, the internet users in Yemen, mobile subscriptions in Syria, the emission of CO2 in Qatar, the exports of fresh oranges and production of electricity in Morocco. the number of shops in Dubai, the production of oil and natural gas in Oman, the participation to the Olympic games by the Arab nations, and the concept of Murabaha in Islamic finance.

We present in what will follow some examples in order to illustrate how mathematical concepts can be applied to real life problems in Arab countries. The applications have been taken from the Arab World Edition of "Introductory Mathematical Analysis for Business, Economics, and the Life and Social Sciences" by Ernest Haeussler, Richard Paul, Richard Wood and Saadia Khouyibaba.

Since the purpose of this presentation is not mathematical solutions of these applications we chose to spare the reader and be limited to a description of these problems.

\section{The exports and imports of Kuwait}

The following graph shows the imports and exports of goods for Kuwait over the period 1988 to $1994^{1}$, in billions of dollars. Estimate the points of intersection from the graph and interpret your answer.

\section{Emaar's Stock value}

The stock value of Emaar Properties, the largest real estate developer in the GCC, for the period between September 1 and October 12, 2010, can be approximated by $E(t)=0.115 t+3.38$, where $t$ is the number of weeks after September $1^{2}$.

a. If $t=0$ corresponds to the period starting September 1, make a table showing the movement of the stock values from September 1st to September 29, 2010. 
b. Supposing that the approximation remains accurate, when will the value of the stock reach 5 dirhams?

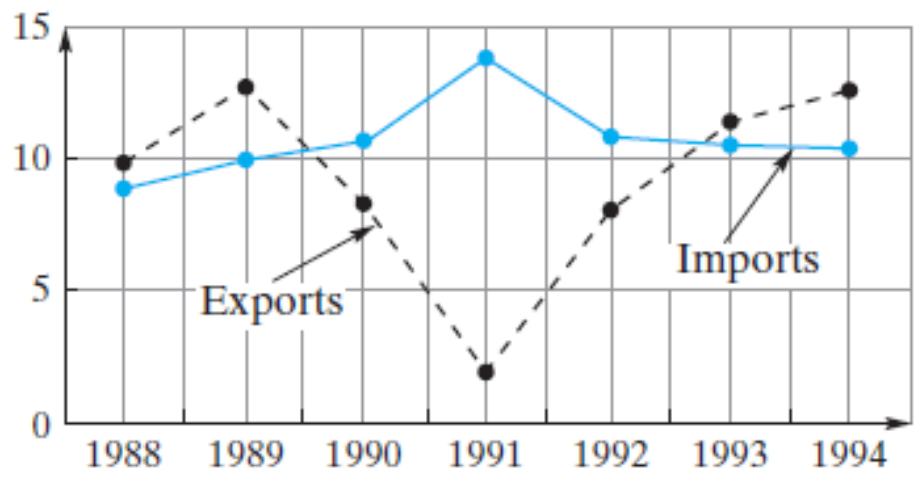

Figure 1: the imports and exports of goods for Kuwait

\section{The number of internet users in Yemen}

Suppose that the number of internet users in Yemen (in thousands) is approximated by the function $f(x)=100(1.228)^{x}$, where $x$ corresponds to the year $2002^{3}$. Find the year in which the number of internet users in Yemen is 800,000 .

\section{Fly Emirates}

In recent years, Emirates Airlines has ranked as the seventh largest airline in the world in terms of international passengers carried, and the largest in terms of scheduled international passengerkilometres flown. The number of passengers (in millions) who flew with Emirates from 2004 to $2010^{4}$ can be modelled by the function $P(x)=0.144 x^{2}+1.97 x+10.44$ where $x$ corresponds to the year 2004

a. Use this model to predict the number of passengers in 2011.

b. In March 2011 Emirates Airlines announced that for the financial year 2010/2011 it carried approximately 85,000 passengers per day. Calculate the error between the result predicted by the model and the actual figure.

\section{CO2 Emissions in Qatar}

Carbon dioxide emissions have been measured in Qatar since 1960 and are observed to be increasing quadratically: The readings for 1965, 1985 and 2005 in thousands of metric tons (kt) are 6287, 12,385, and 56,773 respectively ${ }^{5}$.

a. Use this data to construct a quadratic function that gives the amount of carbon dioxide in year $t$, measured since 1960 .

b. Use this model to estimate carbon dioxide emissions in 2010 and 2015.

\section{The production of electricity in Morocco}

The rate of production of electricity in Morocco for the years 2000 to 2006, measured in billions of kilowatt-hours per year, can be modelled by $E^{\prime}(t)=1201.4340 e^{0.0875 t}$, where $t=0$ corresponds to the year $2000^{6}$. What is the total amount of electricity produced from 2003 to $2006 ?$

\section{Salaries in the GCC countries}

Suppose that the (instantaneous) rate of change of the average salary in the Gulf Cooperative Countries (GCC) is approximated by $S^{\prime}(t)=7+1.82 \ln (t)$ where $S$ is the percentage increase and $t=1$ corresponds to the year $2005^{7}$. According to this model, what was the total salary increase from 2005 to 2007 ?

Throughout these applications, all coming from the Arab World real life, we can see not only that an important variety of topics in mathematics is covered, but also that these applications constitute an 
interesting source of information about this part of the World. This fact makes the student feel directly involved and make him realize that math is all around him which is, in itself, a great gain, as, most of the time, he develops a motivation and a positive attitude towards mathematics. His perception of difficult mathematical concepts improves, and the chance that he makes more efforts to understand and appreciate them will certainly improve.

B. Suppression and replacement of examples, pictures and inappropriate topics

Another important part of adapting this book to the Arab world is the suppression and replacement of examples, pictures and inappropriate topics such as income tax in countries where there are none or discussions that contradict the Islamic religion. Therefore, the opening example of chapter 2: "Suppose a 180-pound man drinks four beers in quick succession. We know that his blood alcohol concentration, or BAC, will first rise, and then gradually fall back to zero. However, what is the best way has been replaced by: to describe how quickly the BAC rises, where it peaks, and how fast it falls again?"
"In the recent years the number of cell phone users has increased considerably. Suppose that we want to know the effects mobile phones have had on fixed-line telephone subscriptions in Egypt, how can we proceed?

We can proceed by obtaining the number (in million) of subscriptions for both mobile and fixed-line telephone services ${ }^{8}$ and displaying them in a table as follows:

Table 1: The number of users of fixed-line telephone in Egypt

\begin{tabular}{c|cccccccc}
\hline Year & 2001 & 2002 & 2003 & 2004 & 2005 & 2006 & 2007 & 2008 \\
\hline Fixed-line & 7.075 & 7.814 & 8.553 & 9.292 & 10.031 & 10.770 & 11.509 & 12.248 \\
\hline
\end{tabular}

Table 2: The number of users of mobile phone in Egypt

\begin{tabular}{c|cccccccc}
\hline Year & 2001 & 2002 & 2003 & 2004 & 2005 & 2006 & 2007 & 2008 \\
\hline Mobile & 4.035 & 3.354 & 4.645 & 6.908 & 13.143 & 20.350 & 29.529 & 40.680 \\
\hline
\end{tabular}

Or approximating them with functions

$$
\begin{gathered}
S_{\text {fixed }}(t)=0.739 t+7.075 \\
S_{\text {mobile }}(t)=0.986 t^{2}-1.667 t+4.035
\end{gathered}
$$

where $t$ is the time measured in years and $t=0$ corresponds to 2001

But "a picture is worth a thousand words" we can then look at the graph of these two functions:

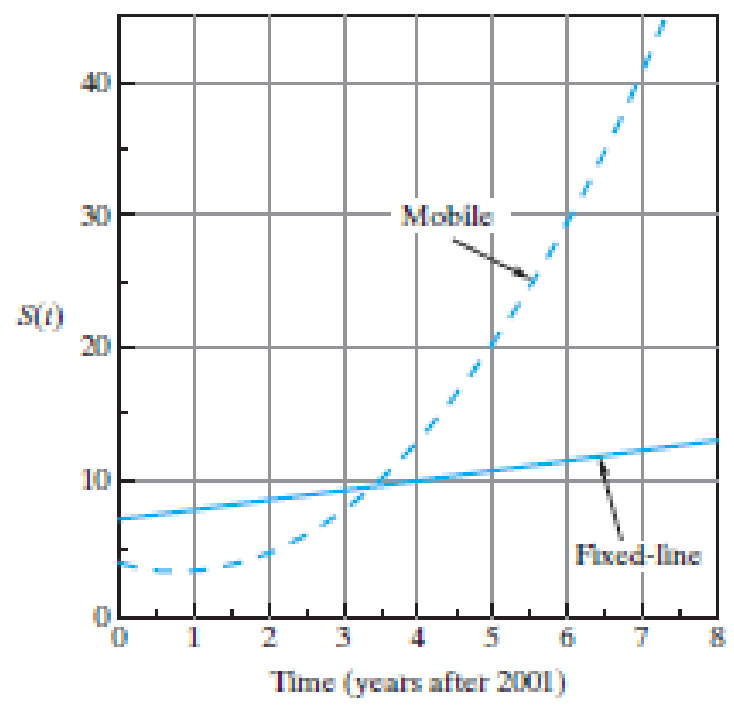


And the example:

"A poker hand consists of 5 cards drawn from a deck of 52 playing cards. The hand is said to be "four of a kind" if four of the cards have the same face value. For example, hands with four 10's or four jacks or four 2's are four-of-akind hands. How many such hands are possible?"

has been replaced by:

"The Kuwait Postal service uses 5-digit zip codes in most cities. How many zip codes are there if the first digit cannot be zero?"

By eliminating and avoiding any discussions considered inappropriate in Arab countries the author shows some respect toward the society where the student lives. In addition, the instructor and the student using this book feel more comfortable since they are not in a situation where they must solve problems involving products completely prohibited in the Muslim religion such as gambling or alcohol. Also throughout the book many photos and illustrations related to the western world were replaced by pictures from the Arab culture.

\section{English-Arabic Glossary}

Mathematical, financial, and economic terms with definition and translation to Arabic have been added to the end of the book. Below are examples to show how this glossary is organized:

- $\quad$ antiderivative| مشتقة عكسية

An antiderivative of a function $f$ is a function whose derivative is $f$

- Equation| معادلة

An equation is a statement that two expressions are equal

- Future value | القيمة المستقبلية

The value, $S$, of a principal $P$ invested at a simple or compound interest rate $r$ for a period of time $t ; S$ amounts to the principal $P$ invested plus the interest I earned on the investment

- Marginal cost| تكلفة حدية

If $c=f(q)$ is the total-cost function for q units of a product, the marginal cost is the rate of change $\frac{d c}{d q}$ interpreted as the approximate cost of one additional unit of output; if $c=f(x, y)$ is a jointcost function of two variables $x$ and $y$, the marginal cost (or partial marginal cost) with respect to $\mathrm{x}$ is the rate of change of $\mathrm{c}$ with respect to $\mathrm{x}$ when $\mathrm{y}$ is held fixed.

Any instructor with experience in the Arab World knows how helpful this is for students who studied Mathematics in high school in Arabic. My personal experience in teaching remedial courses made me learn the problems that these students face during their first year of university. The glossary at the end of the book is provided in order to spare them the trouble of going elsewhere to look up mathematical terms. Therefore, it allows them a smoother reading and helps them to better focus on solving the problem rather than spending time in trying to find the meaning of some mathematical terms.

D. Biographies and Arabic contribution to mathematics

Biographies have been included for prominent and important mathematicians. This historical account gives its rightful place to Arab contributors of this great science that constitutes the mathematics.

In the Islamic Golden Age, scientist would converge from all around the world to institutes such as Bayt Ul-Hikma, the House of Wisdom, in Bagdad. Fibonacci came to Béjaïa, Tunisia, to study the work of Abu Kamil. He is just one example among many others. University of Al-Karaouine in Morocco is the oldest continuously operating academic degree-granting university in the world. The Arabic language was essential during the European Renaissance. Chinese, Indians, Inca, Greeks, Arabs, Persians, Westerners and so many other nations contributed to the fabulous progress of knowledge: any account falls short. But history brings nostalgia to the Arab soul. The Egyptian civilization predates the Greek civilization by two millennia. Great Greek thinkers learned their knowledge in Egypt, adding their own contributions. The Arabo-Islamic civilization, at the apex and at the crossroad of civilizations for centuries, learning from all around the world, perfected the science of mathematics, among others, going as far as introducing fundamental ideas in calculus. 
As example we chose two biographies that were included in the book:

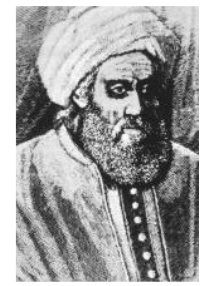

Muhammad Ibn Musa Al-Khwarizmi

c. $780-$ c. 850

Muhammad Ibn Musa Al-Khwarizmi was a Muslim mathematician, born in Uzbekistan, who lived in Baghdad and worked at the famous scientific center called Dar Al Hikmat, ("House of Wisdom"). At the beginning of the ninth century, Al Khwarizmi developed in his famous book Kitab al Jabr wa alMuqabalah the first rules and concepts of algebra. He is also credited with introducing the notion of "algorithm"; indeed, this word itself is a Latinized version of his name.

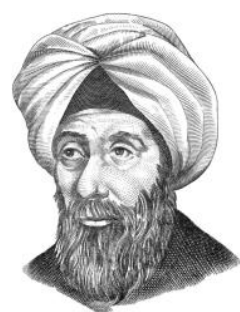

Abu Ali ibn al-Haytham 965-1040

Abu Ali al-Hasan ibn al-Haytham, born in Iraq, was one of the most famous Arab scientists, who left important works in astronomy, mathematics, medicine, and physics. More than 600 years before integrals were known he developed in his manuscript Kitab al Manazir ("Book of Optics") a method to calculate what were, in fact, integrals of fourth-degree polynomials.

In general, history of math can play an important role in the learning process of this science. Any teacher has certainly noticed that when talking about the history of a certain mathematical theory or an anecdote related to a mathematician, students get quickly interested, focus more and want to know more about the subject. Moreover, the interest towards this science becomes stronger when we feel that we are a part of its history. So talking about the Arab contribution in mathematics, without any doubt, revives the pride of students, and this has a very positive effect on the self-confidence and any educator knows that this confidence is one of the most important pillars of the learning process, specially learning mathematics.

\section{Conclusion}

When we started this adaptation we had many concerns about: making connexion between theory and real life problems, about motivation and self-confidence and about the tools that can help in the teaching process.

"When are we going to use math in real life? It's too complicated for nothing!"

How many times we have heard this question in our classrooms? Sometimes providing explanations don't give any results and failed in convincing. So we believe that giving applications from the real life helps a lot and makes students realize that math is everywhere, which leads always to a real motivation to do better and willingness to learn more.

"I'm not very good at math; I do not think I can go through?" It is not uncommon also to hear this concern from the students and we all know that, very often, this is a matter of self-confidence. As instructor in 
this part of the world I can say that giving biographies of Arab mathematicians can help in building this confidence. The student may say: "other eminent Arab mathematicians have excelled in this science so I can succeed there too." I am not saying here that biographies will give the whole necessary selfconfidence needed in learning Math; I'm just saying that this may help a little; the question of confidence in learning math is a "huge" issue and should be treated alone.

"I did math in Arabic in high school, how am I going to do now?" The glossary at the end of the book will definitely help students who are in this situation to have a good academic start in understanding and learning the necessary mathematical terms.

Finally I would like to conclude this presentation by the testimony of one of my former students majoring in Business, Ali Rashed AlMaktoum, about what this book has brought to him:

"Introductory mathematical analysis is an integrated mathematics book which is adapted to meet the needs of the students in the Arab world. Furthermore it consolidates technology (MyMathLab) along with learning, where students can find online help as well as further practice to material questions. This book is different than any other math book, since there has been so much effort put in by the writers to provide students with the knowledge of different math scholars and how their findings are adapted to today's concept of math learning, and this seems to be interesting since it provides an insight of how different equations or calculations have been derived from. Additionally, the questions provided in the book include real-life examples where we might experience or encounter in our daily lives. Though mathematics is viewed by some students as being difficult and uninteresting but once they read this book, it will change their whole perspective of math"

\section{References}

Haeussler, E., Paul, R., Wood, R., Khouyibaba, S., Introductory Mathematical Analysis for Business, Economics, and the Life and Social Sciences (Arab World Editions), Pearson, 2012

Roshdi Rashed (ed.), Encyclopedia of the history of Arabic Science, 3 vols., London and New York, Routledge, 1996.

Faruqi, Yasmeen M. (2006), "Contributions of Islamic scholars to the scientific enterprise", International Education Journal 7 (4): 391-396.

Alhazen, from Wikipedia, the free encyclopedia

\section{Data}

'World Bank, Global Development Finance and International Monetary Fund, Balance of Payments Statistics Yearbook and data files.

${ }^{2}$ Based on data from the Dubai Financial Market: $\underline{\mathrm{http}}$ :// services.dfm.ae/charts/Charts.asp?id=HGPrice\& period=1YR, accessed 2010

${ }^{3}$ Based on data fromwww.indexmundi.com (accessed 2011) and International Telecommunication Union World

Telecommunication/ICT Development Report and database.

${ }^{4}$ Based on data from Emirates Group Annual Reports: http://www.theemiratesgroup.com/english/facts-figures/annualreport.aspx?TYPE=ANNUALREPORT (accessed 2011)

${ }^{5}$ Source: Carbon Dioxide Information Analysis Center, Environmental Sciences Division, Oak Ridge National Laboratory, Tennessee, USA.

${ }^{6}$ Source: International Energy Agency, Energy Statistics of Non-OECD Countries, Energy Balances of Non-OECD Countries, Energy Statistics of OECD Countries, and Energy Balances of OECD Countries

7 Based on data from Gulf Talent, Gulf Compensation Trends 2008

${ }^{8}$ Source: CIA World Factbook, International Telecommunication Union, World Telecommunication/ICT Development Report and database, and World Bank estimates. 